\title{
Penetrance and predictive value of genetic screening in acute porphyria
}

\author{
Baumann, K.
}

2020-05

Baumann , K \& Kauppinen, R 2020 , ' Penetrance and predictive value of genetic screening in acute porphyria ' , Molecular Genetics and Metabolism , vol. 130 , no. 1 , pp. 87-99 . https://doi.org/10.1016/j.ymgr

http://hdl.handle.net/10138/327225

https://doi.org/10.1016/j.ymgme.2020.02.003

draft

Downloaded from Helda, University of Helsinki institutional repository.

This is an electronic reprint of the original article.

This reprint may differ from the original in pagination and typographic detail.

Please cite the original version. 
Regular Article

\title{
Penetrance and predictive value of genetic screening in acute porphyria
}

\author{
Baumann K. ${ }^{\mathrm{a}, \mathrm{b}}$, R. Kauppinen ${ }^{\mathrm{b}, *}$ \\ ${ }^{a}$ Helsinki University Hospital, Department of Obstetrics and Gynecology, Finland \\ ${ }^{\mathrm{b}}$ Helsinki University Hospital, Department of Medicine, Finland
}

\section{A R T I C L E I N F O}

\section{Keywords:}

Acute porphyria

Acute attack

Acute intermittent porphyria

Variegate porphyria

Genetic screening

Penetrance

Diagnosis

Female

\begin{abstract}
A B S T R A C T
Objective: Penetrance, predictive value and female patients' perspectives on genetic testing were evaluated among Finnish patients with acute porphyria. We conducted a retrospective study to evaluate prognosis among at-risk female family members depending on the primary method of diagnosis.

Methods: The penetrance was calculated among 23 genetically heterogeneous families selected from the Finnish porphyria registry ( $n=515$, AIP 333; VP 182). We included kindreds with $\geq 9$ patients in a family (range 9-23 patients, total 216 AIP; 129 VP). In 2015, the registry included 164 living female subjects between 14 and 85 years of age. A questionnaire was sent to 143 women, of whom 107 (75\%, AIP 67; VP 40) replied. Female atrisk relatives (AIP 54; VP 30) were divided into two groups based on the primary method of diagnosis: mutation analysis (Group A, $n=40$ ) or biochemical analysis (Group B, $n=44$ ).

Results: Mean penetrance for all acute symptoms was 35\% among AIP and $40 \%$ among VP families. In both study groups, the penetrance was higher among female (AIP 50\%; VP 44\%) than male patients (AIP 17\%; VP 33\%). Penetrance for hospitalized attacks was 30\% among AIP families (range 10-80\%, for women $41 \%$ ) and $25 \%$ in VP (range $0-50 \%$, for women 27\%) demonstrating wide variations among families even with the similar genotype. Acute porphyria was diagnosed at the median age of 26 years (range 0-76 years) among female patients, commonly after the onset of acute symptoms. Diagnostic delay was an average of 7.4 years (range 1-30 years). Acute symptoms occurred at the median age of 24 years (range 10-57 years) and the first hospitalization at the median age of 26.5 years (range 15-57 years). At the onset of symptoms, $38 \%$ of the women were $\leq 20$ years of age. According to the life table analysis, acute attacks occurred mainly during the following five years after the diagnosis and the attack risk diminished after 35 years of age. The annual risk for hospitalization due to an acute attack during fertile years was lower in Group A than Group B $(0.002$ vs. $0.010, p=.018)$, but the risk of all subsequent acute symptoms did not diminish (Group A 0.017 vs. Group B $0.019, p=.640$ ). The cumulative risk of acute symptoms among asymptomatic patients at the time of diagnosis was $26.7 \%$ for Group A and $58.3 \%$ for Group B. The cumulative risk of the first subsequent attack requiring hospitalization after the diagnosis among all at-risk relatives was similarly less frequent in Group A than in Group B (OR 0.180; 95\% CI 0.041-0.789, $p=.041$ ). If attacks were followed among symptomatic patients only, attack-free years were more frequent in Group A than in Group B. Patients preferred genetic screening before puberty to minimize the risk of acute symptoms and genetic discrimination was rare. $44 \%$ of the patients reported social, psychological or physical impairment due to acute hepatic porphyria, emphasizing the importance of supporting patients' emotional and resilience capacity.

Conclusions: Among female at-risk relatives the annual risk for hospitalization due to an acute attack is $<1 \%$ and for acute symptoms $<2 \%$ during the fertile years. Genetic testing of relatives diminishes the risk of acute attacks. Diagnosis before symptom onset is key for subjects to remain asymptomatic during follow-up, and genetic screening should be done earlier than currently.
\end{abstract}

\section{Introduction}

Acute porphyrias are inherited metabolic diseases that mainly exhibit an autosomal dominant pattern of inheritance caused by partial deficiencies of heme biosynthesis related enzymes [1-3]. They manifest with acute attacks including a combination of autonomic neuropathy

\footnotetext{
Abbreviations: AIP, acute intermittent porphyria; VP, variegate porphyria; AHP, acute hepatic porphyria; PBG, porphobilinogen; DALA, delta-aminolevulinic acid

* Corresponding author at: BOX 705, Biomedicum-Helsinki 2C, 00029 HUS Helsinki, Finland.

E-mail address: Raili.Kauppinen@hus.fi (R. Kauppinen).
} 
(abdominal pain, palpitation), peripheral neuropathy (pain in extremities and back, muscle weakness) and encephalopathy (insomnia, fatigue, restlessness) [4,5]. This is caused by accumulation of porphyrin precursors, which originate mainly from the liver [6]. Acute attacks are commonly induced by multiple exogenous and endogenous factors, which up-regulate ALAsynthase-1, the rate-limiting enzyme in the heme biosynthetic pathway.

Eight genes in the heme biosynthesis are well known. More than 400 mutations have been reported to cause acute intermittent porphyria (AIP, MIM \#176000) and 177 mutations variegate porphyria (VP, MIM \# 176200) $[7,8]$. In Finland, the genetic background for acute porphyrias has been heterogeneous, including the major mutation among VP patients $[9,10]$. Patients with other acute porphyrias, ALAD deficiency porphyria (MIM \#125270) and hereditary coproporphyria (HCP, MIM \#121300), are more rare and have not been identified in Finland to date.

In 2013, the incidence and prevalence have been evaluated in Europe as being 0.13 and 5.9 per million inhabitants for AIP and 0.08 and 3.2 per million inhabitants for VP, respectively [11]. Although the inheritance of mutations causing acute porphyria is equal between men and women $[12,13]$, the vast majority of the porphyria patients with clinical manifestations are women $[9,13]$. This is commonly due to hormonal changes during the luteal phase of the menstrual cycle, which together with other precipitating factors such as fasting, infection, alcohol and certain drugs, may induce attacks [14].

Penetrance has varied from $10 \%$ to $42 \%$ between clinical reports, depending on the inclusion criteria of the clinical outcome and the number of members studied within the families with acute porphyria $[9,11,15,16]$. A population-based study has suggested the penetrance for acute attacks is as low as $1 \%$ for the mutation carriers [17].

Acute attacks have often been misdiagnosed since symptoms of acute porphyria mimic other, more common, causes of abdominal pain or confusion. Attacks can be potentially fatal, with $10 \%$ mortality, if undiagnosed $[9,14,18,19]$. Accurate analysis of porphyrin metabolites during an acute attack is crucial, allowing the early start of an appropriate treatment regimen, which commonly results in the full recovery of the patient [4,20-22]. Genetic testing and counseling of the patients and at-risk family members have decreased the morbidity and severity of an acute attack mainly due to early diagnosis of acute porphyria and avoidance of inaccurate treatment $[9,10]$.

Although genetic testing has been available for more than three decades for acute porphyrias, practical guidelines are scarce [23-25]. Despite the clinical benefits of DNA analysis, it may lead to unpredictable disadvantages such as altering family dynamics, psychological disturbance and insurance or employment discrimination [26].

In this study, we have used the Finnish patient registry for acute porphyria as a backbone for analyzing penetrance among Finnish patients with AIP and VP. We selected a subgroup of 107 female patients to evaluate their morbidity and the predictive value of genetic testing. A questionnaire was used to elucidate female patients' perspectives on genetic testing and diagnosis, and their experience in the health care system.

\section{Subjects and methods}

\subsection{Patients}

We have kept a registry in the Helsinki University Hospital (HUH) that includes all Finnish patients known to have porphyria since 1966 [14,27]. Currently, there are 333 patients with AIP and 182 patients with VP, of whom the study group was set to include women at 14-85 years of age. Of the 182 living female subjects, 164 patients were within this age group in 2015. A questionnaire designed for acute porphyria was sent to 143 patients (91 AIP, $52 \mathrm{VP}$ ), of whom 67 AIP patients (74\%) and $40 \mathrm{VP}$ patients (77\%) were enrolled for the study during 2015 (Fig. 1).
Informed consent was obtained from all study patients, and also from their guardians in case of adolescents. The Ethical Committee of the Department of Medicine, HUH, approved the study protocol.

\subsection{Diagnosis of acute porphyria}

Since 1989, mutation analysis has been performed in 358 family members and patients with AIP and 203 family members and patients with VP. 168 mutation positive patients with AIP (47\% of family members studied) were identified within 39 families representing 27 mutations in the porphobilinogen deaminase gene (PBGD; also known as hydroxymethylbilane synthase, HMBS). 115 mutation positive patients with VP (57\% of all family members studied) represented 25 families and 11 different mutations in the protoporphyrinogen oxidase (PPOX) gene.

The diagnosis of AIP was based either on mutation analysis ( $n=168)$ or typical clinical symptoms associated with elevated porphobilinogen (PBG) and delta-aminolevulinic acid (DALA) levels, low erythrocyte PBGD activity, typical plasma fluorescence emission spectrum $(619 \mathrm{~mm})$ and/or pedigree analysis $(n=165)$. Two subjects were excluded due to inadequate biochemical analysis.

The diagnosis of VP was based either on mutation analysis ( $n=115)$ or characteristic clinical symptoms with increased excretion of fecal protoporphyrin, typical plasma fluorescence emission spectrum $(624 \mathrm{~mm})$, low lymphocyte PPOX activity and/or pedigree analysis $(n=67)$.

\subsection{Biochemical and mutation analyses}

Urinary DALA and PBG were measured using a Bio-Rad (USA) column test [28]. Determinations of urinary excretion of uro- and coproporphyrin and fecal excretion of copro- and protoporphyrin were performed according to Rimington [29] and Holti et al. [30] until 1988, and thereafter using high-pressure liquid chromatography (HPLC) (Varian Inc., US) [31,32]. Plasma porphyrin spectrum was determined with a characteristic fluorescence emission spectrum, $619 \mathrm{~nm}$ for AIP and $624 \mathrm{~nm}$ for VP [33,34]. Enzyme activity was assayed in AIP as PBGD activity [35] and in VP patients as PPOX activity [36].

Mutations found in the Finnish families with acute porphyria have been reported elsewhere [10,37]. In family screening, mutation analysis was performed by isolating DNA from leukocytes, which was amplified using the polymerase chain reaction (PCR) -technique and analyzed using restriction digestion, and/or by direct sequencing. Analyses were repeated at least twice for each sample in the presence of negative and positive controls.

\subsection{Sources of information}

Information about clinical manifestations, biochemical and genetic analysis was obtained from medical reports and our registry. The questionnaire was designed to obtain information about age at diagnosis and onset of symptoms, morbidity, and experiences of standard of care related to porphyria. In addition, the questionnaire inquired into patients' perspectives on genetic screening, genetic counseling and avoidance of precipitating factors as well as the disadvantages concerning an inherited disease.

The severity of clinical symptoms was classified as follows:

1) An acute attack was defined as typical acute symptoms of porphyria such as abdominal pain or pain in the extremities or back associated with autonomic dysfunction, polyneuropathy and mental symptoms in patients with at least a four-fold increase of urinary PBG excretion requiring hospitalization [20].

2) Porphyria-associated acute symptoms were similar but treated at home with symptomatic treatment and commonly no biochemical analysis had been done. 


\begin{tabular}{|c|c|c|c|c|c|}
\hline \multicolumn{6}{|c|}{515 patients with acute porphyria in the Finnish porphyria registry } \\
\hline \multicolumn{3}{|c|}{333 AIP patients } & \multicolumn{3}{|c|}{$182 \mathrm{VP}$ patients } \\
\hline \multicolumn{3}{|c|}{194 alive in 2015} & \multicolumn{3}{|c|}{126 alive in 2015} \\
\hline \multicolumn{3}{|c|}{114 female } & \multicolumn{3}{|c|}{68 female } \\
\hline \multicolumn{3}{|c|}{104 within the age group of $14-85$ years } & \multicolumn{3}{|c|}{60 within the age group of $14-85$ years } \\
\hline $\begin{array}{l}67 \text { subjects } \\
\text { replied to } \\
\text { questionnaire }\end{array}$ & 24 did not reply & $\begin{array}{l}13 \text { could not be } \\
\text { traced }\end{array}$ & $\begin{array}{l}40 \text { subjects } \\
\text { replied to } \\
\text { questionnaire }\end{array}$ & 12 did not reply & $\begin{array}{l}8 \text { could not be } \\
\text { traced }\end{array}$ \\
\hline
\end{tabular}

Fig. 1. Graphical presentation of the subjects enrolled to the study.

3) Recurrent attacks were characterized by at least four attacks yearly requiring hospitalization during the follow-up period.

Skin symptoms in VP were characterized as slowly healing blisters and erosions with crusting and scarring, and excessive skin fragility in solar-exposed areas such as the face and dorsal side of the hands $[10,38]$.

\subsection{Statistical methods}

The chi-square test was used for comparison of categorical variables. Continuous variables were analyzed using Mann-Whitney $U$ test when two groups were compared. Logistic regression was employed to evaluate the association between outcome variables and covariates. Statistical calculations were performed with SPSS version 25 (2017). $P<.05$ was chosen as the level of statistical significance.

\section{Results}

\subsection{Penetrance of AIP and VP}

The penetrance was calculated using female and male patient data from the Finnish porphyria registry. The 23 families selected (AIP, $n=14$; VP, $n=9$ ) included $\geq 9$ patients in a family (Tables 1 and 2). Mean penetrance for all acute symptoms was 35\% among AIP families and $40 \%$ among VP families ( $p=.583$ ) (Fig. 2). In both study groups, the penetrance was higher among female (AIP 50\% and VP 44\%, $p=.603$ ) than male patients (AIP $17 \%$ and VP $33 \%, p=.076$ ), but no significant difference was found between AIP or VP patients.

If the penetrance was calculated only for acute attacks that needed hospitalization, the mean penetrance for AIP patients was 30\% (range $10-80 \%)$ and $25 \%$ (range $0-50 \%$ ) for VP patients $(p=.426)$. The ratio of female to male patients was higher in AIP ( $41 \%$ vs. $17 \% p=.0047)$ but not in VP (27\% vs. $22 \% p=.653)$.

Penetrance for skin symptoms in VP patients was 30\% (34\% female, $27 \%$ male) but a wide variation among families could be detected (Fig. 2e). Interestingly, this variation could also be seen in 7 (103 patients) of 11 VP-families with the Finnish major mutation (c. C454T, p. $\mathrm{R} 152 \mathrm{C}$ ) both in acute (range $30-70 \%$ ) as well as in skin symptoms (range 10-70\%).

Fig. 2a and c demonstrate the within-family proportion of acute attacks in patients with AIP and VP. A penetrance of $>50 \%$ was noted in AIP families with mutations c.1073delA, c.C76T (p.R26C) and c.G593A (p.W198X) in contrast to the lowest penetrance $(\leq 20 \%)$ in families with mutations c.G33T, c.C499T (p.R167W), c.C517T (p.R173W) and c.C673G (p.R225G). In VP families $\geq 50 \%$ penetrance was associated with the mutation c.C454T (p.R152C), but also the lowest $\leq 20 \%$ penetrance was associated with the mutations c.C454T (p.R152C), c.C35T (p.I12T), and c.G338C (del exon 4 ). High penetrance $(\geq 70 \%)$ of acute attacks was associated with families diagnosed and treated before 1980.

Table 1

Mutations and clinical characteristics in AIP families (including index cases).

\begin{tabular}{|c|c|c|c|c|c|c|c|c|c|c|c|c|}
\hline \multirow[t]{2}{*}{ Mutation } & \multirow[t]{2}{*}{ Outcome } & \multicolumn{3}{|c|}{ No. of Patients/Total } & \multicolumn{2}{|c|}{ Gender } & \multicolumn{2}{|c|}{ All acute symptoms } & \multicolumn{2}{|c|}{ Mild to moderate acute symptoms } & \multicolumn{2}{|c|}{ Acute attacks } \\
\hline & & $\mathrm{n}$ & $\mathrm{n}$ & $\%$ & $\mathrm{~F}$ & M & $\mathrm{F}$ & M & $\mathrm{F}$ & M & $\mathrm{F}$ & M \\
\hline c. G33T & Splicing defect & 4 & 22 & 18.2 & 10 & 12 & 2 & 2 & - & - & 2 & 2 \\
\hline c. $33+3 \mathrm{G}>\mathrm{T}$ & Retention of $67 \mathrm{bp}$ fragment intron 1 & 3 & 10 & 30 & 4 & 6 & - & 3 & - & - & - & 3 \\
\hline c. $\mathrm{C} 76 \mathrm{~T}$ & p. R26C & 6 & 10 & 50 & 6 & 4 & 5 & 1 & 1 & - & 4 & 1 \\
\hline c. InsAlu333 & Frameshift & 6 & 16 & 31.3 & 10 & 6 & 6 & - & 1 & - & 5 & - \\
\hline c. A293G & p. K98R & 4 & 11 & 36.4 & 5 & 6 & 3 & 1 & - & - & 3 & 1 \\
\hline c. $\mathrm{C} 346 \mathrm{~T}$ & p. R116W & 5 & 21 & 23.8 & 10 & 11 & 3 & 2 & - & - & 3 & 2 \\
\hline c. $\mathrm{C} 445 \mathrm{~T}$ & p. R149X & 12 & 21 & 47.6 & 14 & 7 & 10 & 2 & 2 & - & 8 & 2 \\
\hline c. $\mathrm{C} 499 \mathrm{~T}$ & p. R167W & 2 & 11 & 18.2 & 5 & 6 & 2 & - & - & - & 2 & 0 \\
\hline c. $\mathrm{C} 499 \mathrm{~T}$ & p. R167W & 1 & 18 & 5.56 & 10 & 8 & 1 & - & - & - & 1 & - \\
\hline c. $\mathrm{C} 517 \mathrm{~T}$ & p. R173W & 6 & 23 & 17.4 & 15 & 8 & 10 & - & 6 & - & 4 & 0 \\
\hline c. G593A & p. W198X & 9 & 12 & 75 & 5 & 7 & 5 & 4 & - & - & 5 & 4 \\
\hline c. $\mathrm{C} 673 \mathrm{G}$ & p. R225G & 5 & 17 & 17.6 & 8 & 9 & 5 & - & 2 & - & 3 & - \\
\hline c. $\mathrm{C} 673 \mathrm{~T}$ & p. R225X & 8 & 15 & 33.3 & 8 & 7 & 6 & 2 & 3 & - & 3 & 2 \\
\hline c. 1073 delA & Frameshift & 5 & 9 & 55.6 & 7 & 2 & 5 & - & - & - & 5 & - \\
\hline Total & & 76 & 216 & & 117 & 99 & 63 & 17 & 15 & & 48 & 17 \\
\hline
\end{tabular}


Table 2

Mutations and clinical characteristics in VP families (including index cases).

\begin{tabular}{|c|c|c|c|c|c|c|c|c|c|c|c|c|c|c|}
\hline \multirow[t]{2}{*}{ Mutation } & \multirow[t]{2}{*}{ Outcome } & \multicolumn{3}{|c|}{ No. of Patients/Total } & \multicolumn{2}{|c|}{ Gender } & \multicolumn{2}{|c|}{ All acute symptoms } & \multicolumn{2}{|c|}{ Mild to moderate acute symptoms } & \multicolumn{2}{|c|}{ Acute attacks } & \multicolumn{2}{|c|}{ Skin symptoms } \\
\hline & & $\mathrm{n}$ & $\mathrm{n}$ & $\%$ & $\mathrm{~F}$ & M & $\mathrm{F}$ & M & $\mathrm{F}$ & M & $\mathrm{F}$ & M & $\mathrm{F}$ & M \\
\hline c. C35T & p. $\mathrm{I} 12 \mathrm{~T}$ & 3 & 12 & 25 & 7 & 5 & 2 & 1 & 2 & 1 & - & - & - & - \\
\hline c. $\mathrm{G} 338 \mathrm{C}$ & Exon 4 skipping & 2 & 14 & 14.3 & 10 & 4 & 2 & - & - & - & 2 & - & 3 & - \\
\hline c. $\mathrm{C} 454 \mathrm{~T}$ & p. R152C & 9 & 19 & 47.4 & 11 & 8 & 6 & 3 & 2 & 2 & 4 & 1 & 2 & - \\
\hline c. $\mathrm{C} 454 \mathrm{~T}$ & p. R152C & 7 & 19 & 36.8 & 13 & 6 & 5 & 2 & 2 & 1 & 3 & 1 & 6 & 3 \\
\hline c. $\mathrm{C} 454 \mathrm{~T}$ & p. R152C & 8 & 12 & 66.7 & 6 & 6 & 4 & 4 & 3 & 2 & 1 & 2 & 4 & 4 \\
\hline c. $\mathrm{C} 454 \mathrm{~T}$ & p. R152C & 3 & 11 & 27.3 & 5 & 6 & 3 & - & - & - & 3 & - & 1 & - \\
\hline c. $\mathrm{C} 454 \mathrm{~T}$ & p. R152C & 6 & 16 & 37.5 & 5 & 11 & 3 & 3 & 1 & - & 2 & 3 & 1 & 3 \\
\hline c. $\mathrm{C} 454 \mathrm{~T}$ & p. R152C & 10 & 17 & 58.8 & 10 & 7 & 5 & 5 & 1 & - & 4 & 5 & 2 & 3 \\
\hline c. $\mathrm{C} 454 \mathrm{~T}$ & p. R152C & 3 & 9 & 33.3 & 8 & 1 & 3 & - & 2 & - & 1 & - & 4 & - \\
\hline Total & & 51 & 129 & & 75 & 54 & 33 & 18 & 13 & 6 & 20 & 12 & 23 & 13 \\
\hline
\end{tabular}

\subsection{Clinical manifestations of acute porphyria among fertile women}

The study group consisted of 107 Finnish female patients within the age group of 15-85 years. Clinical manifestations were evaluated during the reproductive years (12-49 years of age), during which the risk for acute symptoms is at the highest. Average follow-up time from the diagnosis was 26 years (range $0-60$ years, median 26.5 years).

$66 \%$ of the patients reported porphyria-associated acute symptoms during the mean follow-up of 32.6 years and $34 \%$ patients no acute symptoms during the mean follow-up of 28.5 years (Fig. 3). $39 \%$ of the patients suffered acute attacks resulting in hospitalization, of whom $57 \%$ suffered repeated attacks. $27 \%$ of the subjects reported only mild to moderate acute symptoms, with no hospitalization. $53 \%$ of patients with VP reported skin symptoms.

Mild to moderate acute symptoms and acute attacks requiring hospitalization were equally frequent in VP and AIP. Patients with VP reported fewer subsequent attacks, and only patients with AIP had recurrent attacks. Attack-free follow-up within the fertile years was compared between patients with AIP and VP using Cox regression survival analysis. The hazard ratios for both acute attacks requiring hospitalization and acute porphyria associated mild to moderate symptoms were comparable between AIP and VP ( $p=.264 ; p=.488)$. Since no statistical difference was observed, both patient groups were analyzed as one (Table 3).

\subsection{Optimal timing of diagnosis}

Acute porphyria was diagnosed at the median age of 26 years (range $0-76)$. Only $2 \%$ of the subjects were diagnosed $\leq 1$ year of age $(n=2)$ and $19 \% \leq 15$ years of age $(n=20) .53 \%$ of the patients were diagnosed by the age of 25 years and $80 \%$ by the age of 35.55 subjects were diagnosed during 1955-1989 and 52 during 1990-2015.

Acute porphyria was diagnosed commonly after the onset of acute symptoms (Fig. 4). Acute symptoms occurred at the median age of 24 years (range 10-57 years) and the first hospitalization at the median age of 26.5 years (range 15-57 years). At the onset of symptoms, 38\% of the women were $\leq 20$ years of age.

Diagnostic delay was an average of 7.4 years (range 1-30 years) among patients with acute symptoms. The maximal diagnostic delay was 13.5 years (range 2-30 years) among the patients with mild to moderate acute symptoms, implying that symptoms associated with porphyria are not recognized. Patients treated at hospital for an acute attack were diagnosed earlier: the mean delay was 4.4 years (range 1-22 years), and 2.9 years (range 1-12 years) for those with subsequent attacks.

23 subjects (AIP 13, VP 10) were index cases in their families and 84 subjects (AIP 54, VP 30) were at-risk relatives. Despite earlier verification of AIP or VP in the family, $36 \%$ of at-risk family members had acute symptoms prior to diagnosis. $21 \%(n=18)$ had mild to moderate acute symptoms for an average of 11 years (range 1-30 years). 5 subjects were not diagnosed until their first acute attack and 7 subjects had already had acute attacks for an average of 1.7 years (range 0.5-8 years) prior to diagnosis, implicating that information was not distributed effectively among family members. Altogether $41 \%$ of the asymptomatic patients $(n=22 / 54)$ became symptomatic during the follow-up after diagnosis (mean 9.8 years, range $0.5-34$ years).

\subsection{Patients' perspective on optimal timing of diagnosis}

According to the patients' perspective, $41 \%$ of the subjects found the timing of the diagnosis appropriate (Table 4). Most of them were mildly affected or asymptomatic, and diagnosed at an early age. None of the patients diagnosed $\leq 15$ years of age reported being tested prematurely. $40 \%$ of the 72 patients with acute symptoms reported being diagnosed too late. $24(83 \%)$ of them were symptomatic prior to or at the time of diagnosis, and $71 \%$ had been hospitalized due to one or several acute attacks before the diagnosis.

103 (96\%) subjects answered a multiple-choice questionnaire (total 111 answers) regarding the preferable age of genetic screening among adults and children (Table 5). The majority preferred genetic screening before puberty, after which the symptoms are more likely to occur. None of the patients refused genetic testing, indicating that they accepted genetic screening as an important part of diagnosis in acute porphyria.

The patients reported that confirmation of acute porphyria was important as such (25\%). This was related to a better understanding of diverse and unspecific symptoms, minimizing the risk of misdiagnosis (17\%), and facilitating appropriate prevention of acute symptoms (19\%) by avoiding triggering factors (33\%). Only 3\% of the female subjects were against genetic screening due to discrimination and the psychological burden it might cause. $20 \%$ of the subjects did not comment.

$5 \%$ of the patients preferred testing at the symptomatic phase because they were concerned about discrimination in insurance and employment policies. Patients' symptoms were mainly the cause of discrimination at work. However, exclusion of acute porphyria with genetic testing was helpful when applying for insurance.

\subsection{Benefits and disadvantages of genetic screening}

42 subjects reported physical, social or psychological impairment due to acute porphyria, the majority of whom were symptomatic ( $86 \%)$. 21 subjects had been hospitalized due to an acute attack, of whom $53 \%$ had subsequent attacks. All patients with recurrent attacks reported physical, social or psychological impairment. $14 \%$ of the subjects were asymptomatic during the follow-up (Fig. 5).

53 subjects reported no physical, social or psychological impairment, $64 \%$ of whom were symptomatic. Eighteen (34\%) subjects had been hospitalized due to an acute attack, and $61 \%$ of them had subsequent attacks. Four patients had skin symptoms solely. 
A) Within-family proportion of acute attacks requiring hospitalization in

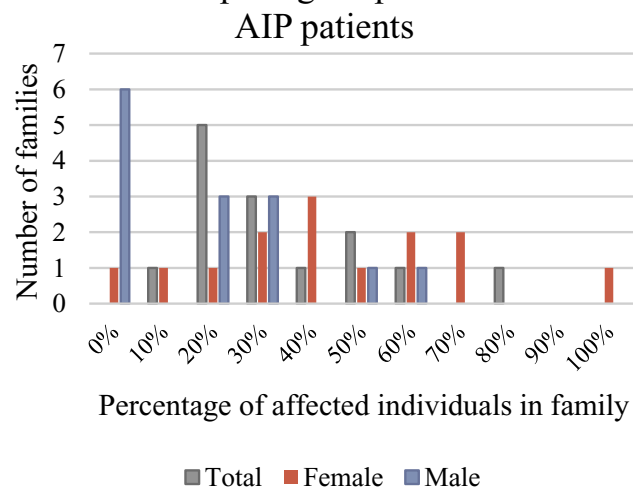

C) Within-family proportion of acute attacks requiring hospitalization in

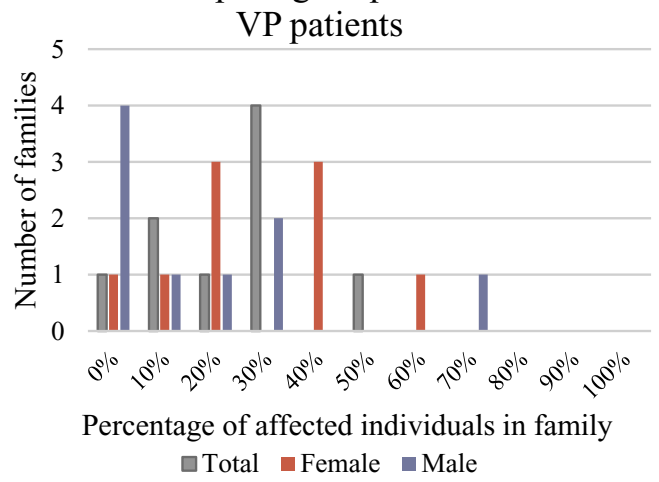

E) Within-family proportion of skin symptoms in VP patients

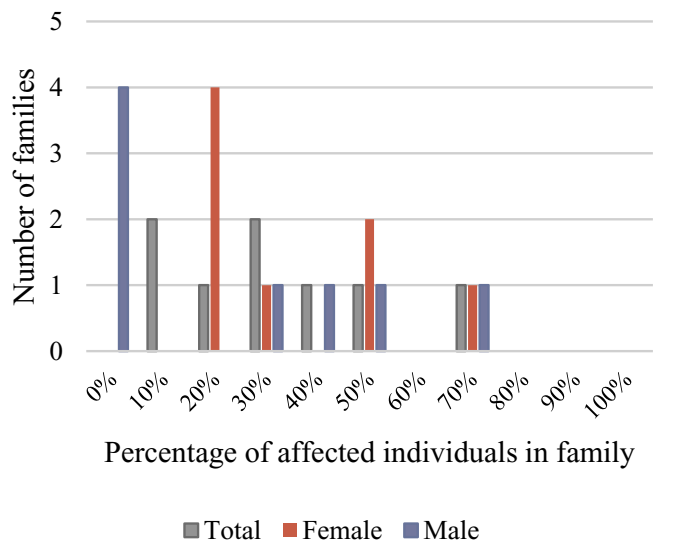

Fig. 2. Within-family proportion of symptoms in both sexes

a) acute attacks in AIP patients:

b) all acute symptoms in AIP patients:

c) acute attacks in VP patients:

d) all acute symptoms in VP patients:

e) skin symptoms in VP patients.

The results indicated that the patients' subjective experience of physical, social or psychological impairment was not only due to the activity of the disease but fear of potential symptoms and mortality. Life-style changes such as observation of body mass index (BMI), avoiding fasting and porphyrinogenic medications, and restricting
B) Within-family proportion of all acute symptoms in AIP patients

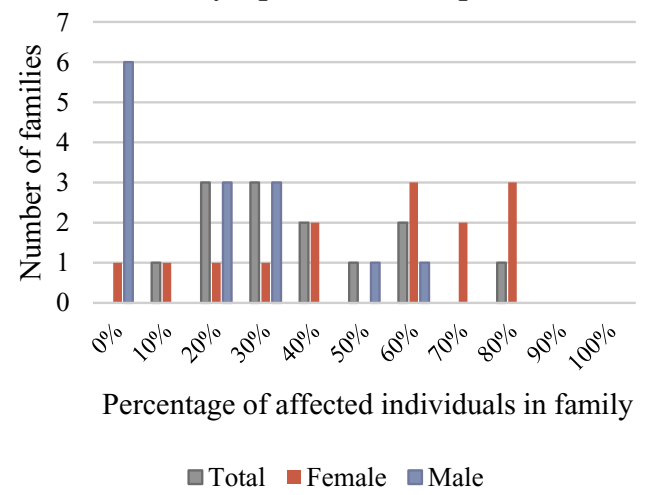

D) Within-family proportion of all acute symptoms in VP patients

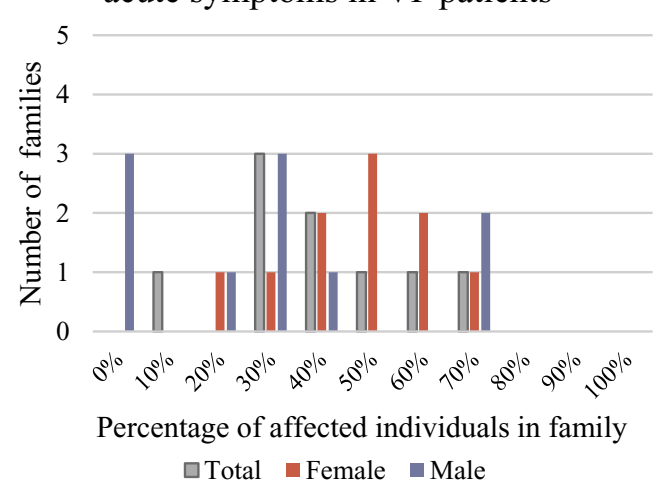

$\square$ Total $\square$ Female $\backsim$ Male alcohol consumption caused additional stress. The burden of transmitting an inherited disease to their offspring affected their opinion.

49 subjects (46\%) reported difficulties within the health care facilities and drug administration due to acute porphyria. 81 subjects (76\%) reported that health care professionals' knowledge of acute 

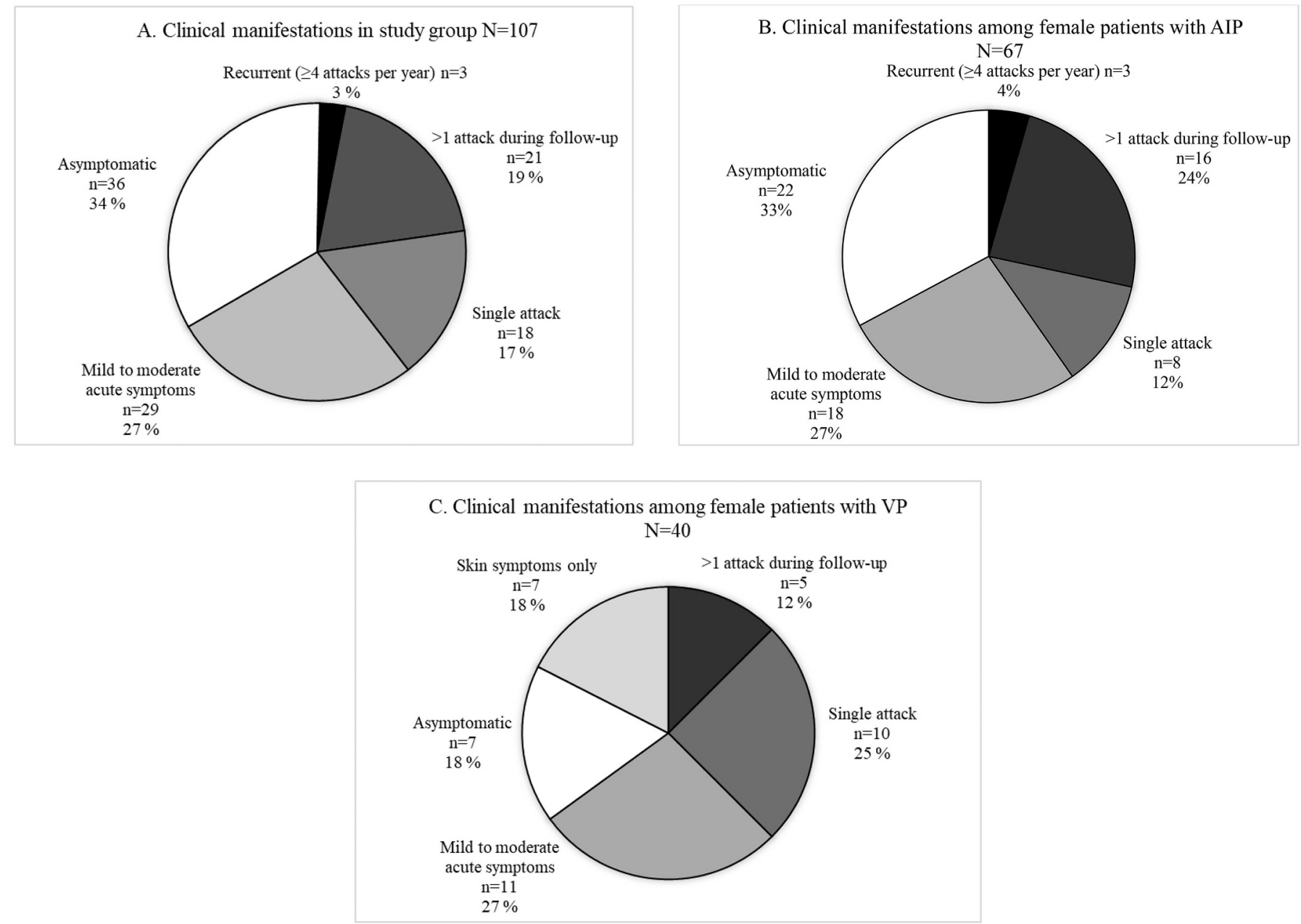

Fig. 3. Distribution of clinical manifestations during follow-up: A. in the study group, B. among patients with AIP, C. among patients with VP.

porphyria was insufficient, and 31 (29\%) subjects reported problems with drug administration. Porphyria dominated physicians' appointments, and patients' other complaints were neglected.

\subsection{Genetic counseling}

In the multi-choice questionnaire (total 123 answers), 67 (63\%) of the 107 patients preferred medical and genetic counseling at a specialists' appointment. Only eight patients (7\%) preferred a family doctor's appointment. 35 patients (33\%) found written information sufficient, and only three patients (3\%) found sufficient information on Finnish or international webpages.

Table 3

Clinical manifestations of 107 female subjects with AIP and VP.

\begin{tabular}{|c|c|c|c|c|}
\hline & AIP & VP & Total & $\mathrm{AIP} / \mathrm{VP} \mathrm{HR}^{\mathrm{a}}(\mathrm{CI})$ \\
\hline Asymptomatic n (\%) & $22(33)$ & $7(18)$ & $29(27)$ & \\
\hline Mild to moderate acute symptoms n (\%) & $18(27)$ & $11(27)$ & $29(27)$ & $1.357(0.573-3.213)$ \\
\hline$>1$ acute attack during follow-up n (\%) & $16(24)$ & $5(12)$ & $21(19)$ & \\
\hline Recurrent attacks ( $\geq 4$ attacks per year) n (\%) & $3(4)$ & - & $3(3)$ & \\
\hline Skin symptoms n (\%) & - & $21(53)$ & - & \\
\hline
\end{tabular}

\subsection{Benefits of genetic screening of at-risk relatives}

We conducted a retrospective study concerning clinical manifestations and prognosis among at-risk family members according to the primary method of diagnosis. Extended family screening was performed using urinary PBG and DALA measurement together with fecal porphyrins and in AIP PBGD activity since 1960, and after 1990 mainly using mutation analysis (Tables 1 and 2). All the patients received genetic counseling by the time of diagnosis, related to precipitating factors and clinical manifestations of acute porphyria.

In the study group of 107 female subjects, 84 at-risk relatives (AIP 54, VP 30) were divided into two groups based on mutation (Group A) or biochemical analysis (Group B). Index cases in the families (AIP 13, VP 10) were excluded. Biochemical and mutation analysis was later

\footnotetext{
${ }^{\mathrm{a}} \mathrm{HR}=$ hazard ratio.
} 


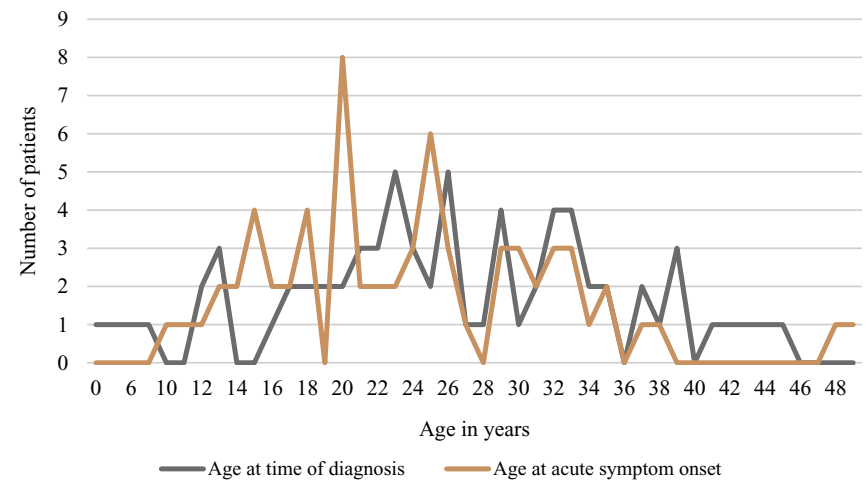

Fig. 4. Distribution of age at the time of diagnosis and onset of acute symptoms.

available to both groups in the majority of cases (Table 6).

To predict the risk of acute symptoms, urinary PBG and DALA excretions were measured during adolescence or adulthood (1-6 analyses per patient) (Fig. 6). Urinary PBG levels were significantly higher in remission among AIP subjects in Group B when compared to those of Group A, and similarly excretion of fecal protoporphyrin in VP patients (Table 6). Half of the AIP patients with acute attacks had elevated urinary PBG levels of $>100 \mu \mathrm{mol} / \mathrm{l}$ in remission.

\subsubsection{Group A}

Genetic testing was performed at a median age of 24 years (Table 6). In Group A, $75 \%$ were asymptomatic at the time of diagnosis, and the majority $(73 \%)$ remained asymptomatic during the follow-up, which averaged 28 years (range 6-68 years) from menarche and 12 years (range 0-26 years) from diagnosis (Table 7). Despite genetic counseling, 8 patients became symptomatic on average 11 years after diagnosis (range 0.5-19 years). Six of them reported mild to moderate acute symptoms, which required no in-patient management, and two patients were hospitalized due to acute attacks.

At genetic counseling, 10 patients $(25 \%)$ had a history of acute symptoms, mean 12 years prior to the diagnosis (range 2-27 years) (Table 7). Two of them became asymptomatic, 8 reported continuation of mild to moderate symptoms, but none of them had severe acute attacks during the follow-up.

\subsubsection{Group B}

Subjects in Group B were diagnosed at a median age of 23 years, and $54 \%$ were asymptomatic at time of the diagnosis (Table 7). During the average follow-up of 35.6 years, 54\% developed acute symptoms, on average 7 years (range 1-34 years) after the diagnosis.

$45 \%$ were symptomatic at the time of diagnosis (Table 7). 11 patients had acute attacks prior to diagnosis, and 5 patients were diagnosed during an acute attack. Additionally, 9 patients had mild to moderate acute symptoms a mean 9.5 years (range 1-30 years) prior to the diagnosis. After the diagnosis, $80 \%$ of the patients remained symptomatic, and $55 \%$ had subsequent attacks.

When Groups A and B were compared, age at the time of diagnosis did not differ substantially. The ratio of symptomatic patients within the study groups at the time of diagnosis was higher in Group B (45\% vs. $25 \%, p=.051$ ). When adjusted for age and duration of follow-up, the annual risk for hospitalization due to an acute attack during fertile years was lower in Group A than Group B (0.002 vs. 0.010, p = .018). The risk of all subsequent acute symptoms did not diminish during the fertile follow-up years (Group A 0.017 vs. Group B 0.019, p = .640).

\subsubsection{Life table analysis}

According to the logistic regression model, predictors of all acute symptoms after diagnosis, adjusted for age at diagnosis and duration of follow-up indicated that patients who had been previously asymptomatic at the time of the diagnosis were less likely to experience acute symptoms during the follow-up than the symptomatic patients (OR 0.141; CI 0.044-0.490, $p=.002$ ). This was especially clear in Group A, but the difference was not statistically significant when compared with Group B (OR 0.327; CI 0.059-1.813, $p=.201$ ).

The cumulative risk of acute symptoms among asymptomatic patients at the time of the diagnosis was $26.7 \%$ for Group A and $58.3 \%$ for Group B (Table 7); according to the life table analysis the hazard ratio between Groups A/B was 0.554 (CI 0.210-1.459) (Fig. 7). The attack risk diminished after 35 years of age. A few women experienced acute symptoms during their menopause when hormonal alterations occur.

The cumulative risk of the first subsequent attack requiring hospitalization after the diagnosis among all at-risk relatives was similarly less frequent in Group A than in Group B (OR 0.180; 95\% CI $0.041-0.789, p=.041$ ) (Fig. 8A). If subsequent attacks were followed among symptomatic patients only, attack-free years were more frequent

Table 4

Timing of the diagnosis according to clinical manifestation.

\begin{tabular}{|c|c|c|c|c|c|c|}
\hline & Asymptomatic & Skin symptoms solely & Mild to moderate acute symptoms & $\geq 1$ acute attack & Median age at diagnosis (range) & Total $n=107(\%)$ \\
\hline Appropriate & 17 & 4 & 15 & 8 & $20(0-76)$ & $44(41)$ \\
\hline Too late & 2 & 1 & 6 & 23 & $26(13-55)$ & $32(30)$ \\
\hline Too early & - & - & - & - & - & 0 \\
\hline Cannot say & 9 & 1 & 8 & 11 & $25(12-53)$ & $29(27)$ \\
\hline Other & - & 1 & - & 1 & - & $2(2)$ \\
\hline
\end{tabular}

Table 5

Optimal timing of genetic screening according to patients' perspective.

\begin{tabular}{|c|c|c|c|c|c|}
\hline \multirow[b]{2}{*}{ Age of testing } & \multicolumn{5}{|c|}{ Patients clinical manifestations } \\
\hline & Asymptomatic & Skin symptoms solely & Mild to moderate acute symptoms & $\geq 1$ acute attack & Total $n=111(\%)$ \\
\hline Prenatal & 1 & - & 1 & 1 & $3(3)$ \\
\hline Newborn & 9 & 4 & 7 & 9 & $29(26)$ \\
\hline $1-5$ years & 5 & - & 8 & 4 & 17 (15) \\
\hline $6-10$ years & 1 & - & 3 & 10 & $14(13)$ \\
\hline $11-14$ years & 9 & 1 & 4 & 10 & $24(22)$ \\
\hline$\geq 15$ years & 4 & 1 & 5 & 8 & $18(16)$ \\
\hline At the symptomatic phase only & 2 & 1 & - & 3 & $6(5)$ \\
\hline No genetic screening & - & - & - & - & - \\
\hline No answer & 2 & - & - & 2 & $4(4)$ \\
\hline
\end{tabular}




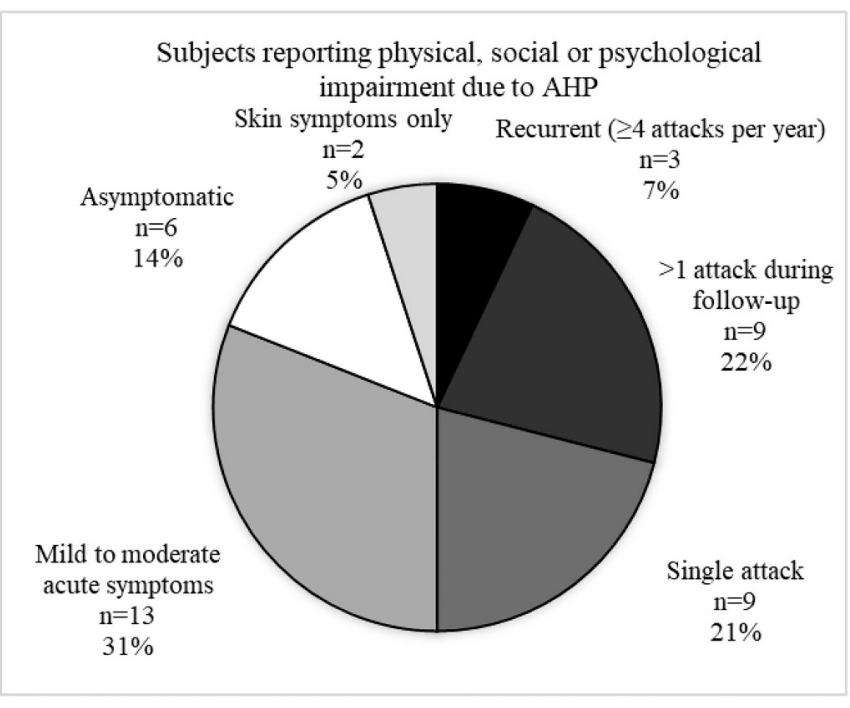

Subjects reporting no physical, social or psychological impairment due to AHP

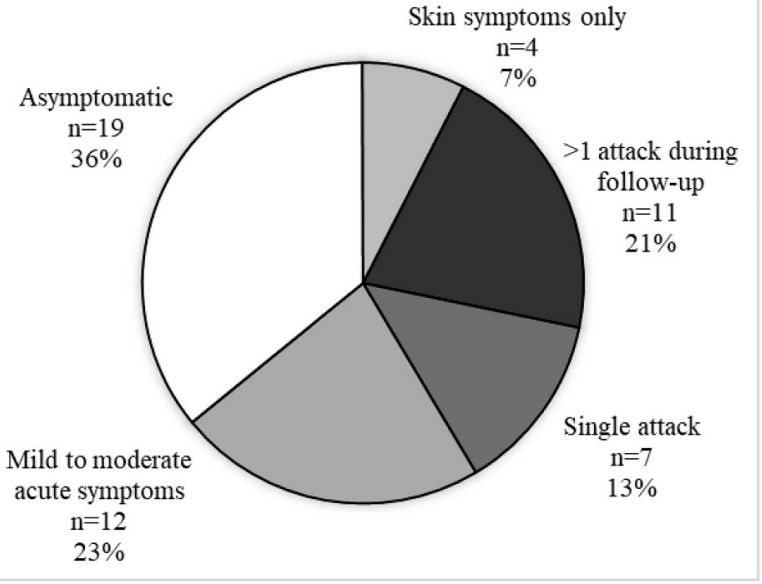

Fig. 5. Subjects' physical, social or psychological impairment according to their clinical manifestations of acute hepatic porphyria (AHP), $n=95$.

in Group A (100\%) than in Group B (44\%), though this was statistically insignificant due to the small number of patients $(p=.184)$ (Fig. 8B). Of note, in Group B the first subsequent attack occurred mainly within the first 5 years after the diagnosis.

\section{Discussion}

In this survey, we used the well-characterized Finnish patient registry including comprehensive number of patients with heterogeneous genetic background and long follow-up time to analyze penetrance, genetic screening and current outcome of the female patients with acute porphyria. Female patients were chosen as a subgroup since around $90 \%$ of the symptomatic patients are currently female despite the fact that the sex ratio of the mutation positive family members is even $[9,39,40]$. Outcome of acute porphyria is highly dependent on patients' hormonal status and symptoms occur after the onset of puberty $[14,39,41]$. The personal contact during the follow-up years explains the high response rate for the questionnaires, providing us reliable information about the patients' symptoms and well-being. The questionnaire was specially designed for AHP and not validated due to the rarity of the disease.
Table 6

Demographics of groups A and B.

\begin{tabular}{|c|c|c|c|}
\hline $\begin{array}{l}\text { Group } \mathrm{A}=\text { genetic testing } \\
\text { Group } \mathrm{B}=\text { biochemical testing }\end{array}$ & $\begin{array}{c}\text { Group A } \\
n=40 \\
\text { (AIP 25, VP 15) }\end{array}$ & $\begin{array}{c}\text { Group B } \\
\mathrm{n}=44 \\
\text { (AIP 29, VP 15) }\end{array}$ & $P$-Value \\
\hline Year of diagnosis & 1989-2015 & 1955-2012 & \\
\hline $\begin{array}{l}\text { Age in years in 2015; mean } \\
\text { (range) median }\end{array}$ & $\begin{array}{c}39(15-80) \\
36\end{array}$ & $\begin{array}{c}58(27-85) \\
58\end{array}$ & $<0.001$ \\
\hline $\begin{array}{l}\text { Age in years at diagnosis; mean } \\
\text { (range) median }\end{array}$ & $\begin{array}{c}28(0-76) \\
24\end{array}$ & $\begin{array}{c}23(3-44) \\
23\end{array}$ & 0.287 \\
\hline $\begin{array}{l}\text { Follow-up fertile years; mean } \\
\text { (range) person years } \\
\text { Tested later with both methods n } \\
\quad(\%)\end{array}$ & $\begin{array}{c}24(3-37) \\
954 \\
33 / 40 \\
(83 \%)\end{array}$ & $\begin{array}{c}35(15-37) \\
1546 \\
34 / 44 \\
(77 \%)\end{array}$ & $<0.001$ \\
\hline \multirow[t]{2}{*}{$\begin{array}{l}\text { U-PBG in remission; median } \\
\quad \text { (range) normal }<9 \mu \mathrm{mol} / 1\end{array}$} & $\begin{array}{l}\text { AIP } 13 \\
(4-200)\end{array}$ & $\begin{array}{l}\text { AIP } 52 \\
(7-515)\end{array}$ & 0.019 \\
\hline & $\begin{array}{c}\text { VP } 6 \\
(2-30)\end{array}$ & $\begin{array}{l}\text { VP } 13 \\
(1-35)\end{array}$ & 0.283 \\
\hline \multirow[t]{2}{*}{$\begin{array}{l}\text { U-DALA in remission; median } \\
\quad \text { (range) normal }<34 \mu \mathrm{mol} / 1\end{array}$} & $\begin{array}{l}\text { AIP } 35 \\
(7-94)\end{array}$ & $\begin{array}{l}\text { AIP } 59 \\
(4-410)\end{array}$ & 0.108 \\
\hline & $\begin{array}{l}\text { VP } 35 \\
(8-56)\end{array}$ & $\begin{array}{l}\text { VP } 38 \\
(16-52)\end{array}$ & 0.297 \\
\hline $\begin{array}{l}\text { F-Protoporphyrin in remission; } \\
\text { median (range) normal } \\
<130 \mathrm{nmol} / \mathrm{g} \text { (dry feces) }\end{array}$ & $\begin{array}{l}\text { VP } 60 \\
(24-640)\end{array}$ & $\begin{array}{l}\text { VP } 416 \\
(23-1254)\end{array}$ & 0.013 \\
\hline
\end{tabular}

\subsection{Penetrance in AIP and VP}

Penetrance for acute attacks was $25 \%$ for VP and 30\% for AIP patients among Finnish porphyria families, which is in line with the $10-42 \%$ estimated for AIP in other countries for both sexes $[9,11,13,15,16]$. In VP, the penetrance of acute attacks has shown a decreasing tendency from $38 \%$ to $14 \%$ in Finland, especially among men during the last three decades $[9,10]$. Low penetrance of acute attacks $(4 \%)$ has also been detected from a large family carrying the South African major mutation (R59W) [42]. In both series, however, penetrance of skin manifestations has been similar and more common (30-40\%) than acute symptoms suggesting different pathophysiology.

According to our study, no significant difference was detected between acute attacks of AIP or VP over six decades, but there was a considerable variation within the Finnish families in both diseases (e.g. $10-80 \%$ in AIP; $0-50 \%$ in VP). This indicates that the individual risk for acute symptoms depends more on sex, other modifying genes and exogenous factors than the disease-causing mutation $[3,9,43,44]$.

Female patients with AIP were the most frequently affected, with a high penetrance of $41 \%$ for acute attacks and $50 \%$ for all acute symptoms related to porphyria. This phenomenon has also been detected among women with a high rate of acute attacks (55\%) and subsequent attacks (39\%) in the Swedish families with the major mutation (W198X) in northern Sweden [16,39]. In addition, a high percentage ( $81 \%)$ of symptomatic female patients has been reported from the patient series in USA [40]. Most acute symptoms are self-reported but patients with acute porphyria commonly recognize porphyric symptoms well. Since excretion of porphyrin metabolites in the urine is often increased more than 4-fold even in remission [9,14,20], the diagnosis of an acute attack is clinical, mainly based on patients' reported symptoms, and on exclusion of other causes for complaints.

Most of the severe acute attacks among Finnish women were reported before 1990 's, but even after mutation analysis became common, $2.8 \%$ of the women experienced severe attacks regularly. This is in line with the figure of $1-7.5 \%$ estimated from other European countries based on the incidence calculations for both sexes during 2007-2009 $[11,45]$.

\subsection{Diagnostic delay}

Based on our survey, the average age at the time of diagnosis was 


\section{Urinary excretion of PBG and DALA in remission in Groups A and B}

600

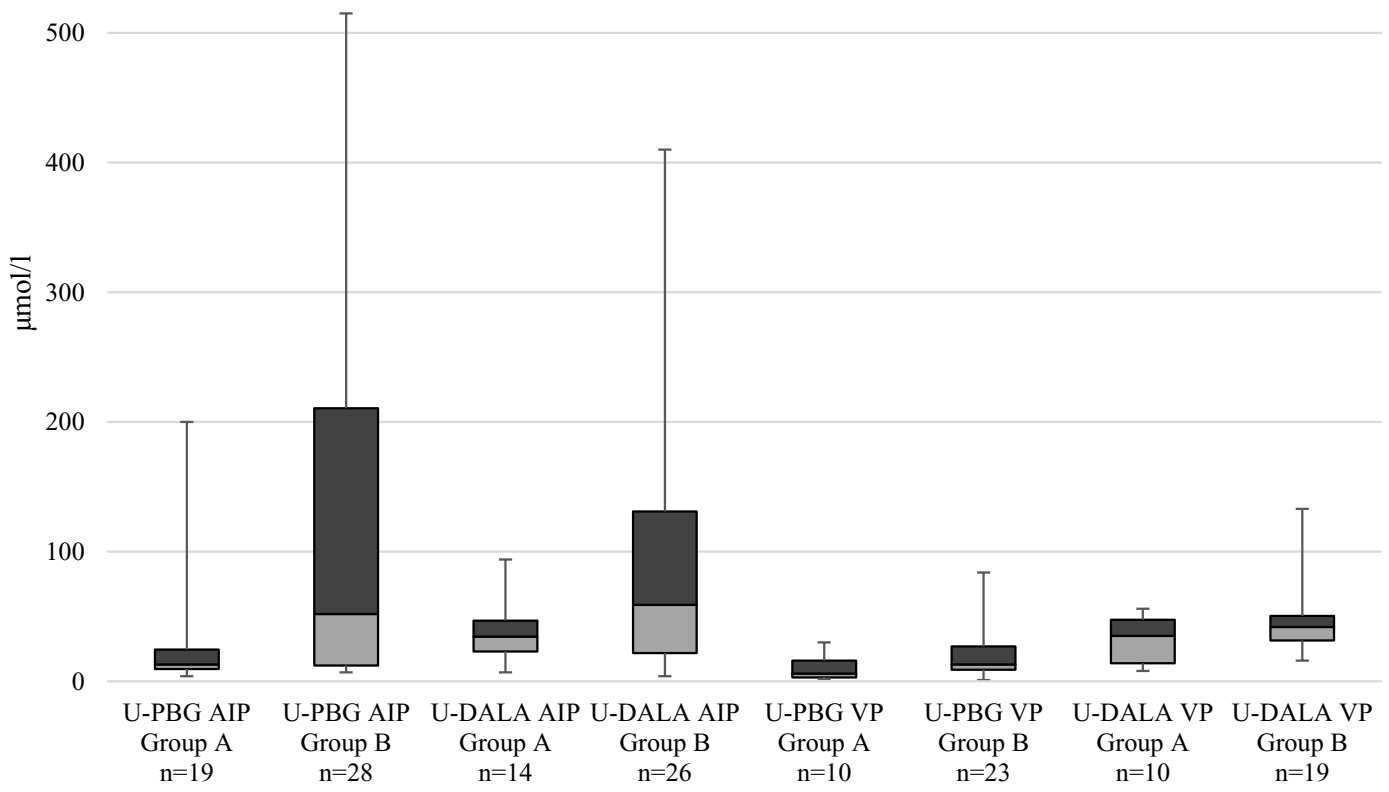

Fig. 6. Distribution of urinary PBG and DALA in remission, measured in Groups A and B separately among AIP and VP subjects. U-PBG normal < $9 \mu$ mol/l, U-DALA normal $<34 \mu \mathrm{mol} / \mathrm{l}$.

26 years but the range was wide, often due to family screening after an index case. Mean age at the onset of acute symptoms was 1-2 years earlier, indicating that many patients had already had acute symptoms prior to the diagnosis of acute porphyria.

Patients regarded severe, often undiagnosed, acute attacks unbearable, and thus, many of them considered that the timing of the diagnosis was too late. Delay in diagnosis has often been long, 7.4 years on average in our survey. This is mainly because clinicians have not been acquainted with the symptoms of acute porphyria. Patients have also avoided hospitalization due to previous negative experiences [46]. Similar diagnostic challenges have also been reported from other countries with symptom onset at 20-30 years of age and diagnostic delay up to 15 years $[16,40,44]$. Even repeated attacks were undiagnosed, although the delay has been shorter than in single attacks. Fortunately, early genetic screening and easy access to on-line medical databases will improve the knowledge of porphyria among health care professionals, and patients are no longer the only source of information related to the disease.

The prevalence of acute symptoms that did not result in hospitalization was surprisingly high (18\%) prior to the diagnosis and has persisted despite genetic counseling and avoidance behavior. Results imply that acute porphyria-related symptoms are still unrecognized and untreated, although an acute attack can easily be detected by urinalysis of porphyrin precursors. Although all precipitating factors, such as

Table 7

Acute symptoms among patients in Group A and B at time of diagnosis and during follow-up.

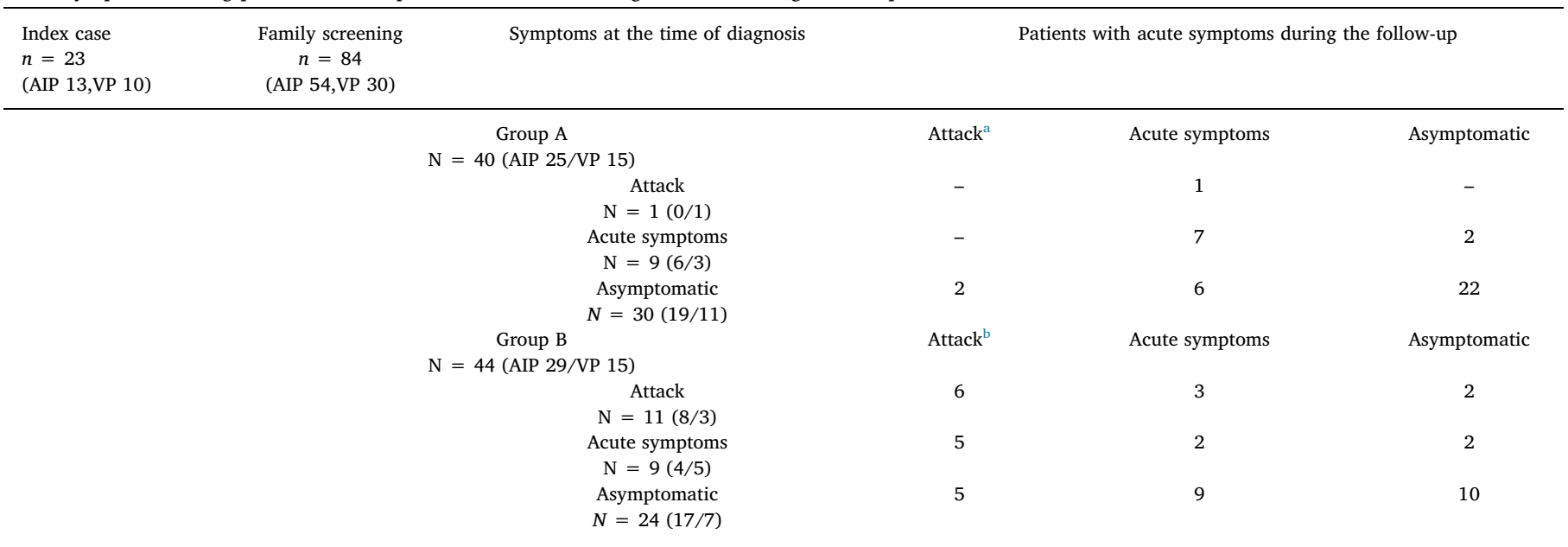

First subsequent attacks treated.

a 2005-2013.

b 1967-2013. 


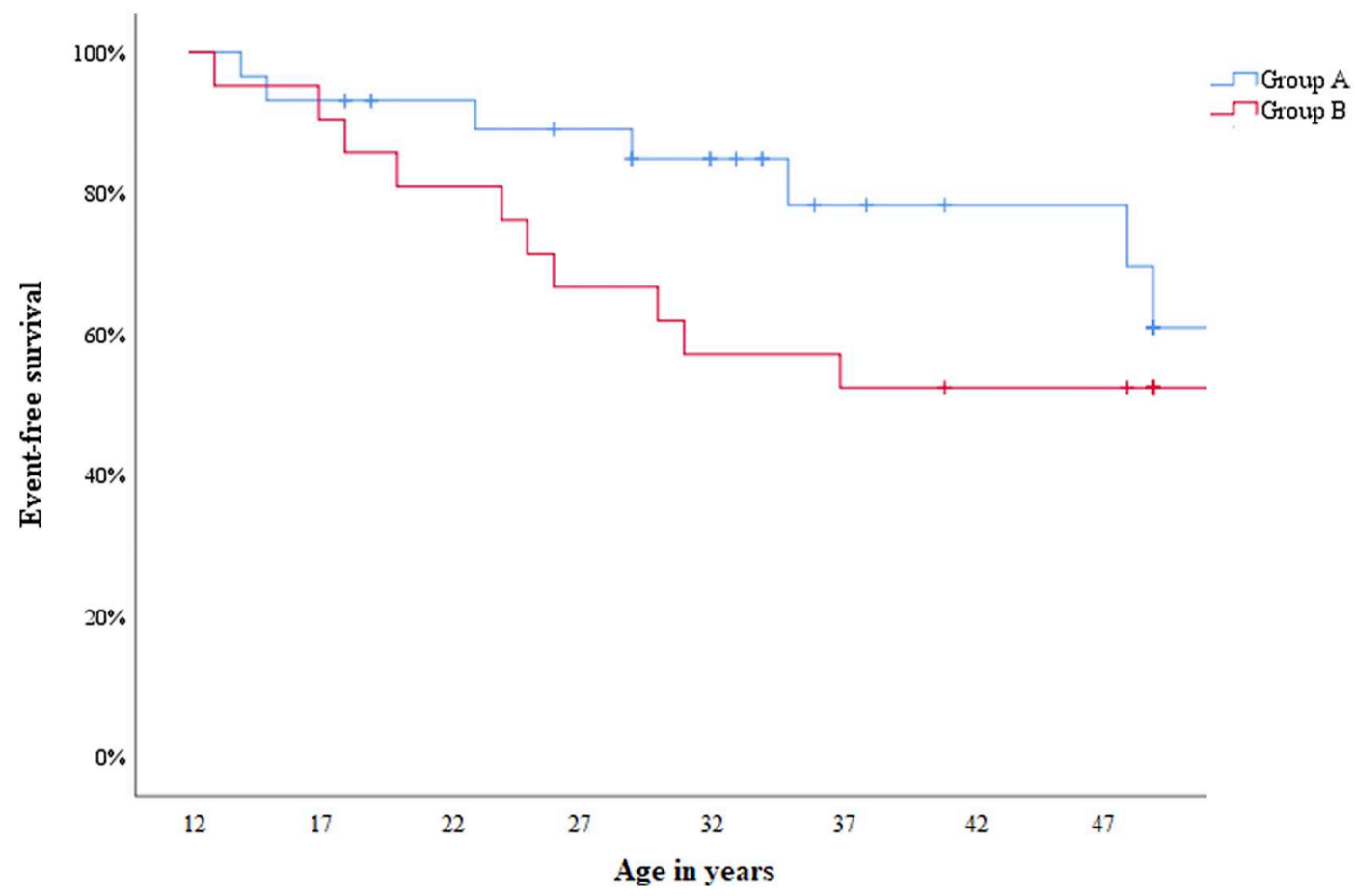

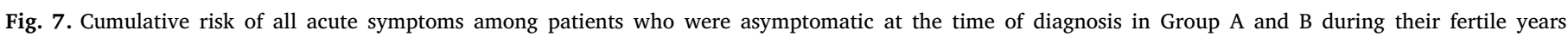
(12-49 years of age).

hormonal changes, are not easy to control $[41,47]$, they should be actively managed from the onset of symptoms to avoid progressive manifestations of the disease. According to our patient data, symptomatic women typically experience acute symptoms within 35 years of age and five years after diagnosis. Recurrent acute symptoms commonly result in chronic neurologic deficit and a poor quality of life $[4,46,48]$. Prevention of symptoms with hormonal therapies, hemin or givosiran, and maintaining normal weight is crucial and may stop a patient's vicious circle $[1,22]$.

\subsection{Genetic testing}

Combining targeted mutation analysis with evaluation of biochemical activity is essential when identifying patients at risk for acute attacks [25]. In primary diagnosis, mutation analysis has become the golden standard for screening of at-risk families, which is justifiable with a $95 \%$ sensitivity and $100 \%$ specificity, if pathogenicity of a mutation (class 4 or 5) is confirmed [12,49]. Genetic testing reveals patients with mild symptoms and lower excretions of porphyrin precursors, which have been otherwise difficult to diagnose.

Biochemical analysis, especially measurement of urinary PBG has a lower sensitivity of $84 \%$ and specificity of $71 \%$ but is the method of choice during an acute attack, and may also have predictive value among asymptomatic patients with AIP [12].

According to our results, urinary PBG excretion was substantially higher in remission among patients in Group B, and acute attacks were more frequently treated at hospital. The difference between Groups A and B could be explained by the activity of the disease due to constant up-regulation of ALAS1 induced by environmental factors, other modifying genes and proneness for neuropathy after the first attack.

Based on life table analysis and logistic regression model, patients diagnosed at the asymptomatic phase have a significantly lower risk of developing acute symptoms during their life-span. This was particularly seen among patients diagnosed primarily with genetic testing. Moreover, symptomatic patients diagnosed with genetic testing experienced no attacks requiring hospitalization after diagnosis, but a substantial number described mild to moderate acute symptoms. Home- treated attacks have become a more common pattern of management, indicating that acute symptoms have become milder and preferably treated at home.

Based on patients-perspectives, genetic screening should be performed earlier than it currently is. Most patients preferred genetic screening before puberty to minimize the risk of acute symptoms. Patients' opinion on genetic testing was in general positive, although mutation analysis verified the diagnosis of an inherited disease, which can be transmitted to their offspring. Genetic discrimination was rare, and mainly associated with private insurance policies among both adults and children.

Primarily predictive genetic screening is recommended to be delayed until children can decide for themselves. However, genetic testing can occur with parental consent, if testing aims at treatment or prevention as in acute porphyria, where the results emphasize that early screening of gene carriers is important for prevention of conversion to manifest acute porphyria and severe recurrent attacks $[16,50]$.

Considering the dramatic decrease of mortality and morbidity in acute porphyria during the last decades due to avoidance of porphyrinogenic drugs and use of target treatment $[9,10]$, we recommend mutation analysis to be performed preferably before the age of 14 years to identify family members at risk.

\subsection{Genetic counseling}

More than half of the patients reported no social, psychological or physical impairment despite acute symptoms, emphasizing the importance of patients' emotional capacity and resilience. Genetic counseling was considered important, and symptomatic patients in particular preferred counseling by a specialist and written information. Timing of counseling may vary and depend on a patient's needs and clinical manifestations. Surprisingly, $38 \%$ of the symptomatic female patients in our survey had already experienced acute symptoms before 21 years of age. Although adolescence may be a sensitive age, young mutation carriers should be informed about triggering factors and the importance of beneficial life-style changes [24]. Patients would benefit from education and self-management of their disease, and they should 
A.

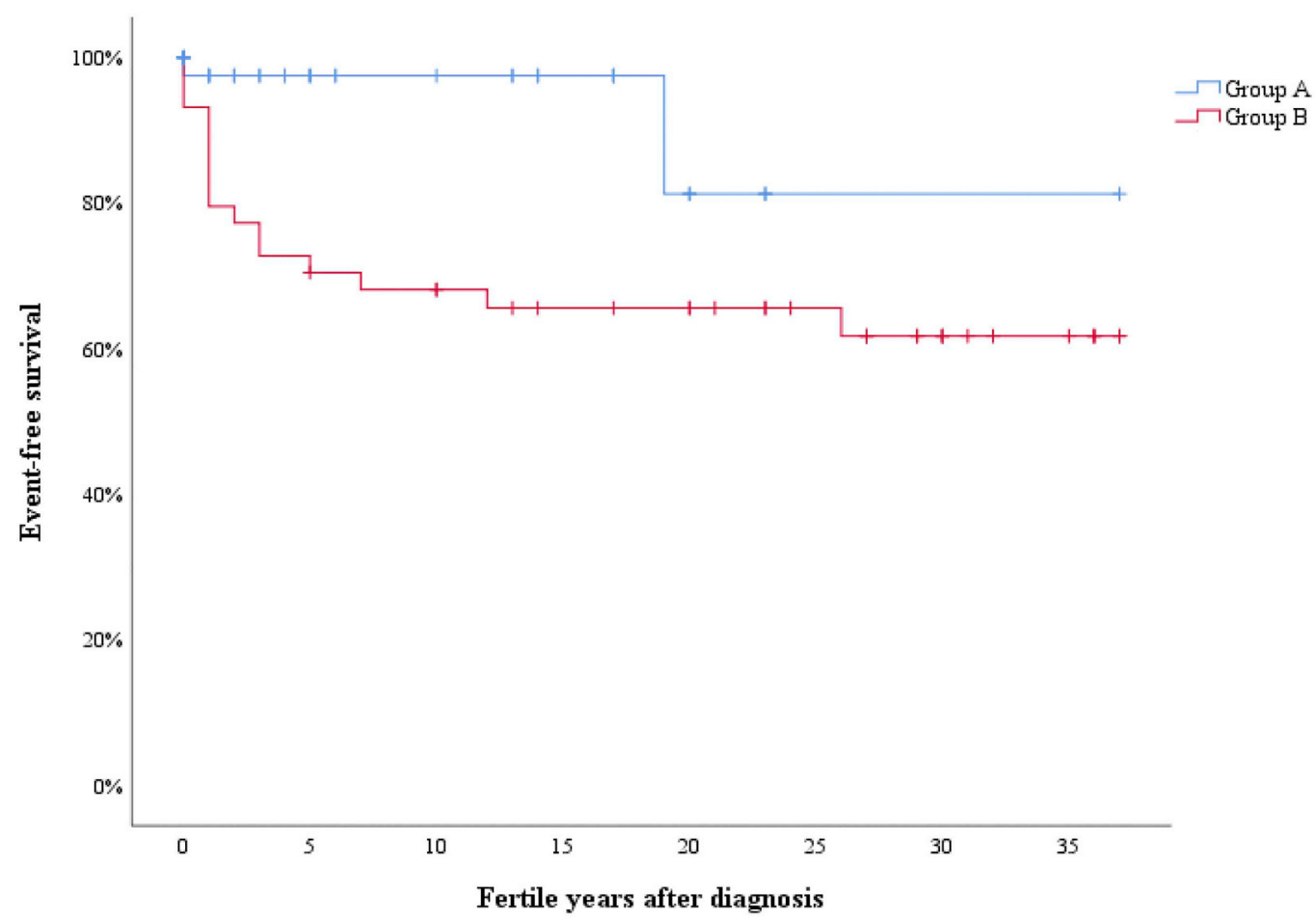

B.

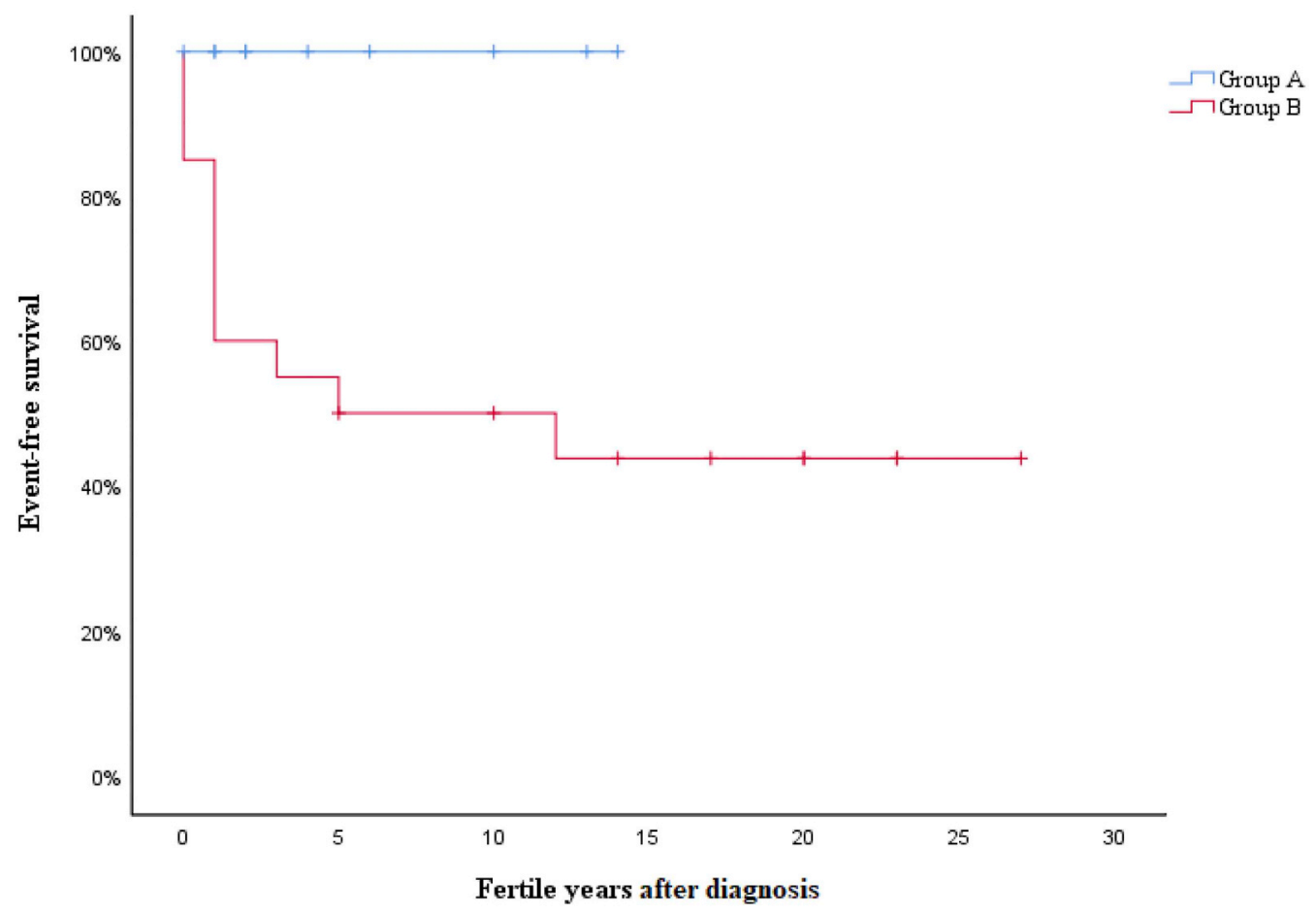

Fig. 8. Life table analysis of Group A and B. Cumulative risk of the first subsequent attack requiring hospitalization after the diagnosis A) among all at-risk relatives and $B$ ) among patients with acute symptoms before diagnosis.

be aware of preventive treatment options and helpful contact possibilities.

During counseling, patients' symptoms and signs should be analyzed carefully to identify potential manifestations of acute porphyria, and to exclude non-porphyric symptoms for their proper treatment. Measurement of urinary porphyrin precursors provides predictive information in AIP [14], since high excretion indicates proneness for clinical manifestations. Moreover, normal fecal excretion of 
protoporphyrins predicts no porphyric symptoms in patients with VP [10].

\section{Conclusions}

Female patients with AIP were the most frequently affected, with a high penetrance of $41 \%$ for acute attacks and $50 \%$ for all acute symptoms related to porphyria. Annual risk for hospitalization among VP and AIP female patients was $<1 \%$ and for acute symptoms $<2 \%$ during the fertile years but the risk diminished after 35 years of age. Wide variation in penetrance was detected between families even with similar genotypes, indicating that individual risk for acute symptoms depends more on sex, other modifying genes and exogenous factors than the disease-causing mutation.

Genetic screening of relatives seems to diminish the risk of severe attacks. Diagnosis before symptom onset is key for a subject to remain asymptomatic during the follow-up, and genetic screening should be performed earlier than currently. Delay in diagnosis has often been long and most patients preferred genetic screening before puberty to minimize the risk of acute symptoms. During counseling, patients' symptoms should be analyzed carefully to identify manifestations of acute porphyria and provide efficient treatment at the early phase of symptoms. The prevalence of acute symptoms, which did not result in hospitalization, was high and persisted despite genetic counseling and avoidance behavior.

\section{Author contributions}

$\mathrm{KB}$ and RK contributed to the design of the study, and data collection, analysis and interpretation. KB drafted the initial manuscript and RK revised the manuscript. Both authors have accepted responsibility for the entire content of this submitted manuscript and approved submission.

\section{Funding}

This research was funded by research grant from Helsinki University Hospital.

\section{Declaration of Competing Interest}

KB has no conflicts of interest relevant to this article to disclose. RK has received financial support from Alnylam and Clinuvel pharmaceuticals in addition to Orion pharmaceuticals and Sanofi pharmaceutical company.

\section{Acknowledgments}

We thank V. Varho, MD PhD, for advice for statistics and data analysis.

\section{References}

[1] D.M. Bissell, K.E. Anderson, H.L. Bonkovsky, Porphyria, N.Engl.J.Med. 377 (2017) $862-872$.

[2] H.L. Bonkovsky, J.T. Guo, W. Hou, T. Li, T. Narang, M. Thapar, Porphyrin and heme metabolism and the porphyrias, Compr.Physiol. 3 (2013) 365-401.

[3] M. Yasuda, B. Chen, R.J. Desnick, Recent advances on porphyria genetics: inheritance, penetrance \& molecular heterogeneity, including new modifying/causative genes, Mol.Genet.Metab. 128 (2019) 320-331.

[4] E. Pischik, R. Kauppinen, Neurological manifestations of acute intermittent porphyria, Cell. Mol. Biol. (Noisy-le-grand) 55 (2009) 72-83.

[5] N.G. Simon, G.K. Herkes, The neurologic manifestations of the acute porphyrias, J.Clin.Neurosci. 18 (2011) 1147-1153.

[6] D.M. Bissell, J.C. Lai, R.K. Meister, P.D. Blanc, Role of delta-aminolevulinic acid in the symptoms of acute porphyria, Am.J.Med. 128 (2015) 313-317.

[7] P.D. Stenson, M. Mort, E.V. Ball, K. Evans, M. Hayden, S. Heywood, M. Hussain, A.D. Phillips, D.N. Cooper, The human gene mutation database: towards a comprehensive repository of inherited mutation data for medical research, genetic diagnosis and next-generation sequencing studies, Hum.Genet. 136 (2017) 665-677.

[8] The Genome Aggregation Database (gnomAD), https://gnomad.broadinstitute.org, (2019).

[9] M. von und zu Fraunberg, E. Pischik, L. Udd, R. Kauppinen, Clinical and biochemical characteristics and genotype-phenotype correlation in 143 Finnish and Russian patients with acute intermittent porphyria, Medicine (Baltimore) 84 (2005) $35-47$.

[10] M. von und zu Fraunberg, K. Timonen, P. Mustajoki, R. Kauppinen, Clinical and biochemical characteristics and genotype-phenotype correlation in Finnish variegate porphyria patients, Eur.J.Hum.Genet. 10 (2002) 649-657.

[11] G. Elder, P. Harper, M. Badminton, S. Sandberg, J.C. Deybach, The incidence of inherited porphyrias in Europe, J.Inherit.Metab.Dis. 36 (2013) 849-857.

[12] R. Kauppinen, M. von und zu Fraunberg, Molecular and biochemical studies of acute intermittent porphyria in 196 patients and their families, Clin.Chem. 48 (2002) 1891-1900.

[13] M.M. Schuurmans, X. Schneider-Yin, U.B. Rufenacht, C. Schnyder, C.E. Minder, H. Puy, J.C. Deybach, E.I. Minder, Influence of age and gender on the clinical expression of acute intermittent porphyria based on molecular study of porphobilinogen deaminase gene among Swiss patients, Mol.Med. 7 (2001) 535-542.

[14] R. Kauppinen, P. Mustajoki, Prognosis of acute porphyria: occurrence of acute attacks, precipitating factors, and associated diseases, Medicine (Baltimore) 71 (1992) 1-13.

[15] J.M. Lamon, B.C. Frykholm, D.P. Tschudy, Family evaluations in acute intermittent porphyria using red cell uroporphyrinogen I synthetase, J.Med.Genet. 16 (1979) $134-139$.

[16] I. Bylesjo, A. Wikberg, C. Andersson, Clinical aspects of acute intermittent porphyria in northern Sweden: a population-based study, Scand.J.Clin.Lab.Invest. 69 (2009) 612-618.

[17] B. Chen, C. Solis-Villa, J. Hakenberg, W. Qiao, R.R. Srinivasan, M. Yasuda, M. Balwani, D. Doheny, I. Peter, R. Chen, R.J. Desnick, Acute intermittent porphyria: predicted pathogenicity of HMBS variants indicates extremely low penetrance of the autosomal dominant disease, Hum.Mutat. 37 (2016) 1215-1222.

[18] Y.P. Liu, W.C. Lien, C.C. Fang, T.I. Lai, W.J. Chen, H.P. Wang, ED presentation of acute porphyria, Am.J.Emerg.Med. 23 (2005) 164-167.

[19] J.B. Jeans, K. Savik, C.R. Gross, M.K. Weimer, I.C. Bossenmaier, C.A. Pierach, J.R. Bloomer, Mortality in patients with acute intermittent porphyria requiring hospitalization: a United States case series, Am.J.Med.Genet. 65 (1996) 269-273.

[20] P. Mustajoki, Y. Nordmann, Early administration of heme arginate for acute porphyric attacks, Arch.Intern.Med. 153 (1993) 2004-2008.

[21] R. Tenhunen, P. Mustajoki, Acute porphyria: treatment with heme, Semin.Liver Dis. 18 (1998) 53-55.

[22] E. Pischik, R. Kauppinen, An update of clinical management of acute intermittent porphyria, Appl.Clin.Genet. 8 (2015) 201-214.

[23] S.D. Whatley, M.N. Badminton, Role of genetic testing in the management of patients with inherited porphyria and their families, Ann.Clin.Biochem. 50 (2013) 204-216.

[24] J. Andersen, S. Sandberg, M. Raaheim, E. Gjengedal, Psychosocial aspects of predictive genetic testing for acute intermittent porphyria in norwegian minors, JIMD Rep. 1 (2011) 1-7.

[25] R. Kauppinen, Molecular diagnostics of acute intermittent porphyria, Expert Rev. Mol. Diagn. 4 (2004) 243-249.

[26] B. Godard, S. Raeburn, M. Pembrey, M. Bobrow, P. Farndon, S. Aymé, Genetic information and testing in insurance and employment: technical, social and ethical issues, Eur. J. Hum. Genet. 11 (2003) 123-142.

[27] P. Mustajoki, P. Koskelo, Hereditary hepatic porphyrias in Finland, Acta Med. Scand. 200 (1976) 171-178.

[28] D. Mauzerall, S. Granick, The occurrence and determination of 5-aminolevulinic acid and porphobilinogen in urine, J.Biol.Chem. 219 (1956) 435-446.

[29] C. Rimington, Quantitative Determination of Porphobilinogen and Porphyrin in Urine and Faeces, 21 Association of Clinical Pathologist Broadsheet, 1958.

[30] G. Holti, C. Rimington, B.C. Tate, G. Thomas, An investigation of porphyria cutanea tarda, Q. J. Med. 27 (1958) 1-18.

[31] F. Li, C.K. Lim, T.J. Peters, Analysis of urine and faecal porphyrins by HPLC coupled to an advanced automated sample processor, Biomed.Chromatogr. 1 (1986) 93-94.

[32] C.K. Lim, T.J. Peters, Urine and faecal porphyrin profiles by reversed-phase highperformance liquid chromatography in the porphyrias, Clin. Chim. Acta 139 (1984) 55-63.

[33] R. Enriquez de Salamanca, P. Sepulveda, M.J. Moran, J.L. Santos, A. Fontanellas, A. Hernandez, Clinical utility of fluorometric scanning of plasma porphyrins for the diagnosis and typing of porphyrias, Clin.Exp.Dermatol. 18 (1993) 128-130.

[34] M.B. Poh-Fitzpatrick, A.A. Lamola, Direct spectrofluorometry of diluted erythrocytes and plasma: a rapid diagnostic method in primary and secondary porphyrinemias, J. Lab. Clin. Med. 87 (1976) 362-370.

[35] R.E. Ford, C.N. Ou, R.D. Ellefson, Assay for erythrocyte uroporphyrinogen I synthase activity, with porphobilinogen as substrate, Clin.Chem. 26 (1980) 1182-1185.

[36] J.C. Deybach, H. de Verneuil, Y. Nordmann, The inherited enzymatic defect in porphyria variegata, Hum.Genet. 58 (1981) 425-428.

[37] R. Kauppinen, S. Mustajoki, H. Pihlaja, L. Peltonen, P. Mustajoki, Acute intermittent porphyria in Finland: 19 mutations in the porphobilinogen deaminase gene, Hum.Mol.Genet. 4 (1995) 215-222.

[38] K. Timonen, K.M. Niemi, P. Mustajoki, R. Tenhunen, Skin changes in variegate porphyria. Clinical, histopathological, and ultrastructural study, Arch.Dermatol.Res. 282 (1990) 108-114.

[39] C. Andersson, E. Innala, T. Backstrom, Acute intermittent porphyria in women: 
clinical expression, use and experience of exogenous sex hormones. A populationbased study in northern Sweden, J.Intern.Med. 254 (2003) 176-183.

[40] H.L. Bonkovsky, V.C. Maddukuri, C. Yazici, K.E. Anderson, D.M. Bissell, J.R. Bloomer, J.D. Phillips, H. Naik, I. Peter, G. Baillargeon, K. Bossi, L. Gandolfo, C. Light, D. Bishop, R.J. Desnick, Acute porphyrias in the USA: features of 108 subjects from porphyrias consortium, Am.J.Med. 127 (2014) 1233-1241.

[41] A. Ahangari, T. Backstrom, E. Innala, C. Andersson, S. Turkmen, Acute intermittent porphyria symptoms during the menstrual cycle, Intern.Med.J. 45 (2015) 725-731.

[42] R.J. Hift, D. Meissner, P.N. Meissner, A systematic study of the clinical and biochemical expression of variegate porphyria in a large south African family, Br.J.Dermatol. 151 (2004) 465-471.

[43] H. Lenglet, C. Schmitt, T. Grange, H. Manceau, N. Karboul, F. Bouchet-Crivat, A. Robreau, G. Nicolas, J. Lamoril, S. Simonin, A. Mirmiran, Z. Karim, E. Casalino, J. Deybach, H. Puy, K. Peoc'h, L. Gouya, From a dominant to an oligogenic model of inheritance with environmental modifiers in acute intermittent porphyria, Hum. Mol. Genet. 27 (2018) 1164-1173.

[44] R.J. Hift, P.N. Meissner, An analysis of 112 acute porphyric attacks in Cape Town, South Africa: evidence that acute intermittent porphyria and variegate porphyria differ in susceptibility and severity, Medicine (Baltimore) 84 (2005) 48-60.

[45] C. Schmitt, H. Lenglet, A. Yu, C. Delaby, A. Benecke, T. Lefebvre, P. Letteron, V. Paradis, S. Wahlin, S. Sandberg, P. Harper, E. Sardh, A.K. Sandvik, J.R. Hov, A.K. Aarsand, L. Chiche, C. Bazille, J.Y. Scoazec, J. To-Figueras, M. Carrascal, J. Abian, A. Mirmiran, Z. Karim, J.C. Deybach, H. Puy, K. Peoc'h, H. Manceau, L. Gouya, Recurrent attacks of acute hepatic porphyria: major role of the chronic inflammatory response in the liver, J.Intern.Med. 284 (2018) 78-91.
[46] H. Naik, M. Stoecker, S.C. Sanderson, M. Balwani, R.J. Desnick, Experiences and concerns of patients with recurrent attacks of acute hepatic porphyria: a qualitative study, Mol.Genet.Metab. 119 (2016) 278-283.

[47] E. Innala, T. Backstrom, M. Bixo, C. Andersson, Evaluation of gonadotropin-releasing hormone agonist treatment for prevention of menstrual-related attacks in acute porphyria, Acta Obstet. Gynecol. Scand. 89 (2010) 95-100.

[48] R.A. Neeleman, M.A.E.M. Wagenmakers, R.H. Koole-Lesuis, G.S. Mijnhout, J.H.P. Wilson, E.C.H. Friesema, J.G. Langendonk, Medical and financial burden of acute intermittent porphyria, J.Inherit.Metab.Dis. 41 (2018) 809-817.

[49] B. Chen, S. Whatley, M. Badminton, A.K. Aarsand, K.E. Anderson, D.M. Bissell, H.L. Bonkovsky, M.D. Cappellini, Y. Floderus, E.C.H. Friesema, L. Gouya, P. Harper, R. Kauppinen, Y. Loskove, P. Martasek, J.D. Phillips, H. Puy, S. Sandberg, C. Schmitt, J. To-Figueras, Y. Weiss, M. Yasuda, J.C. Deybach, R.J. Desnick, International Porphyria molecular diagnostic collaborative: an evidence-based database of verified pathogenic and benign variants for the porphyrias, Genet.Med. 21 (2019) 2605-2613.

[50] L. Gouya, P. Ventura, M. Balwani, D.M. Bissell, D.C. Rees, U. Stolzel, J.D. Phillips, R. Kauppinen, J.G. Langendonk, R.J. Desnick, J.C. Deybach, H.L. Bonkovsky, C. Parker, H. Naik, M. Badminton, P.E. Stein, E. Minder, J. Windyga, R. Bruha, M.D. Cappellini, E. Sardh, P. Harper, S. Sandberg, A.K. Aarsand, J. Andersen, F. Alegre, A. Ivanova, N. Talbi, A. Chan, W. Querbes, J. Ko, C. Penz, S. Liu, T. Lin, A. Simon, K.E. Anderson, EXPLORE: A prospective, multinational, natural history study of patients with acute hepatic porphyria with recurrent attacks, Hepatology (2019), https://doi.org/10.1002/hep.30936 [Epub ahead of print]. 